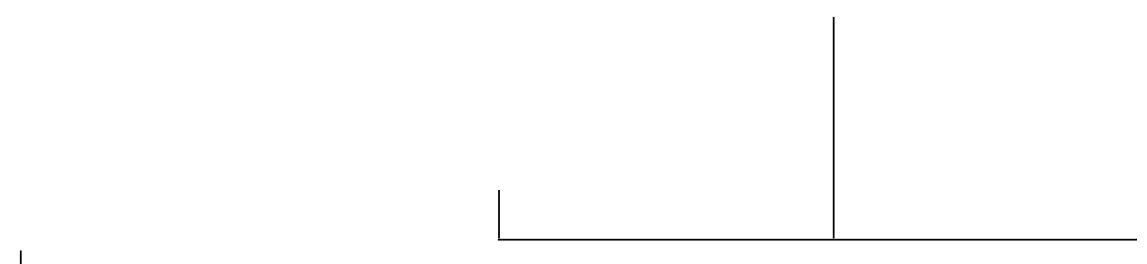

Rev. Latinoam. Psicopat. Fund., São Paulo, v. 15, n.3, p. 618-622, setembro 2012

\title{
A insistência em existir
}

\author{
Fabiano Massarro Salvador
}
Porque quando te não vejo, deixastes de existir. E se se tem saudades do que não existe, Sinto-a em relação a cousa nenhuma; Não é do navio, é de nós, que sentimos saudade. (Alberto Caeiro, $O$ guardador de rebanhos e outros poemas).

Uma narrativa sobre o poeta lisboeta Fernando Pessoa, poderia ter início da seguinte forma. "Ele nasceu, trabalhou, morreu." Sem sombra de dúvida tais questões ontológicas repousam e desdobram-se numa miríade infindável de aspectos. Estes são penetrados por mais força quando falamos de uma personalidade ou uma personagem como Pessoa.

Curiosa, entretanto, é a evocação da figura de Fernando Pessoa: ela se apresenta de forma não tão poética, uma imagem sem corpo, vaga, fragmentada, lembrando acessórios, como os inesquecíveis óculos, chapéu e bigode. Uma caricatura infantil remetendo não só ao homem como à sua vasta obra.

Onde nascera, trabalhara e morrera o soberbo poeta? Isso importa?

Fernando Pessoa viveu ou existiu de formas bastante peculiares. Lendo sua obra, bem como a de seus comentadores e biógrafos, fica-se diante de um cosmo complexo pertencente a uma categoria existencial em que as letras têm o poder de arrancar o leitor do tempo e do espaço e lançá-lo a um universo onde orbitam palavras sublimes, prenhes de delicadeza e plenas 


\section{MOVIMENTOS}

LITERÁRIOS

de clareza. Para existir Pessoa teve de se desdobrar - fingir, ludibriar, escrever e acreditar nas vozes a falar ao coração e ao espírito.

Esses artifícios foram de grande valia para sua obra, a tal ponto que de sua mente prodigiosa uma multidão de heterônimos surgiram. Ser um grande poeta é em si uma proeza homérica, que se dirá ser ao menos quatro. Desses quatro, Pessoa ao longo de sua vida criou mais de setenta heterônimos dentre estes, personagens curiosas.

Feliz é o livro que retrata e sugere questões bastante sobre estes e outros aspectos.

O livro é de Richard Zenith e Joaquim Vieira (2011). A obra literalmente fala por si, pois apresenta um Fernando Pessoa distinto ... em trânsito, em movimento.

Além do rico material documental e fotográfico, os autores apontam, mas sem querer revelar, muitas das questões que envolveram a vida do poeta. $\mathrm{O}$ trânsito refere-se a um curioso aspecto de sua vida. As fotografias prediletas de Pessoa eram as que ele estava a caminhar. Eram o resultado de uma série de fotos escolhidas por ele, tarefa difícil de ser realizada, pois não se achava um sujeito dotado de beleza, muito menos um homem sensual.

Desde a adolescência mostrara uma compleição franzina, frágil. Na infância, teve que treinar "ginástica respiratória" com um professor, pois um de seus maiores temores era sofrer de tuberculose, uma vez que, quando contava quatro anos de idade, seu pai e seu irmão faleceram por conta de tal patologia. Outro mais amedrontador era o medo da loucura. Pessoa temia as terríveis forças invisíveis podendo lhe alcançar o espírito, degenerando sua tão querida razão.

A gênese da heteronímia parece ter brotado logo após a morte do pai e do irmão. Nessa época, seu primeiro amigo imaginário foi Chevalier de Pas. Inicia-se, assim, uma curiosa correspondência de Monsieur Chevalier para Fernando, com apenas cinco anos. É possível pensar, então, que a criação de heterônimos, amigos imaginários, sejam mecanismos de defesa bastante elaborados com o propósito de manter Pessoa diminuto, pequenino, em um mundo ideal.

Falar em melancolia acerca de Fernando Pessoa talvez seja precipitado e corriqueiro. A sombra abatendo-se sobre o poeta, e uma possível e arriscada interpretação, transcende essa categoria psicopatológica.

A vida sempre pareceu revelar-se opressora. Desde a infância, as brincadeiras com outras crianças deram lugar à leitura de livros e ao cultivo da solidão. Solidão que a posteriori era reclamada à mãe. A atitude ambivalente de Pessoa sempre deixava rastros, cacos, tanto em sua vida como em sua obra. Seria possível, então, tomá-la como um mosaico bizantino, de igual beleza, mas concebido de fragmentos.

Pessoa acalentava sonhos de ser um empresário, desde que tal atividade não lhe ocupasse tempo demasiado, pois sua vida era ler e escrever. O poeta leu tudo 
ou quase tudo que havia de melhor, lia os filósofos gregos e alemães, tinha admiração pelos poetas simbolistas franceses, em especial Arthur Rimbaud. Detinha-se também nas obras de Shakespeare e Milton, e do americano Walt Whitman.

Uma obra teve para ele um sabor especial, ficou nela durante muito tempo. O livro de Max Nordau sobre degenerescência o impressionou sobremaneira. Influenciado por tal obra, Pessoa criou um agrupamento de nomes para resistir à ação inexorável do tempo a se inscrever no corpo e na vida. Seus temores em relação à tuberculose e à loucura, com o passar dos anos, parecem se apaziguar. Dizia não acreditar em Deus, porém a obra que começava a escrever a passos largos deveria servir à humanidade e a Deus.

Seus escritos começam a pulular aqui e ali, vindos de origens diversas, de nomes diversos, ora Alberto Caeiro, Álvaro de Campos, Ricardo Reis e Bernardo Soares. Entendia-se com todos, mas quando os assuntos eram mais secretos, íntimos, tinha pequeno diário onde escrevia suas impressões em inglês e assinava com o nome de Charles Robert Anon.

Seus queridos heterônimos eram seus amigos, conhecidos de longa data, inexistentes vidos e ouvidos. Essas contradições lembram as traquinagens infantis, pueris em sua irreverência, ricas em detalhes, ao mesmo tempo doces e mentirosas.

Pessoa parecia querer brincar em vez de crescer. Quando esta última característica fora tentada, revelou-se um fracasso. Ao receber sua herança, Pessoa cria a Impressora e Editora Íbis que irá atolar-se em dívidas portentosas ao cabo de um ano. Assim Pessoa descobre sua própria incompetência prática e abandona a aspiração de ser um homem do comércio. Recusa trabalhos com horários fixos. Ambicionava receber uma quantia suficiente para não trabalhar muito (outra contradição em termos).

Este é o período marcado pela transitoriedade, crises financeiras, reveses da vida e do próprio espírito. Pessoa perambula pela cidade, pelos cafés, fica em quartos de hotéis sentindo-se cada vez mais só, amargurado e com o coração aflito, pesado. Alternando momentos de isolamento e movimento. Inicia, nessa fase, um desejo de saber acerca das religiões e práticas esotéricas com o intuito de apaziguar sua mente e seu corpo.

Lê avidamente obras teosóficas, cabalísticas, alquímicas, astrológicas, maçônicas, rosacruzes. Começa a praticar a chamada "escrita automática" e escreve cartas aos borbotões, traça mapas astrais de figuras históricas importantes, de amigos e de si. Manda cartas aos espíritos com quem diz ter estreito contato, alia-se ao mago inglês Aleister Crowley, figura altamente controvertida. Ajuda Crowley, na caverna Boca do Inferno, em Cascais, a simular suicídio. Admite ter o poder de ver a aura das pessoas, inclusive a sua própria, 


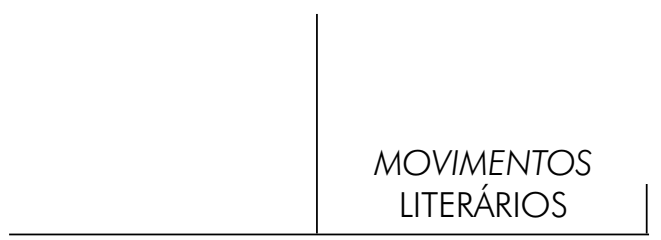

no espelho. Encanta-se com essa possibilidade outra de conhecimento, começa a assinar os mapas e as cartas automáticas com o nome de Rafael Baldaia. Cogita a possibilidade de vir a tornar-se astrólogo, mas desiste da empreitada.

Talvez pela autossugestão e o saber crescente sobre as ciências ditas herméticas e ocultas, vozes e espíritos começam a assombrá-lo. As vozes provêm de dentro de sua cabeça, acusando-o de onanista e de artista incompleto.

Essas forças fazem com que Pessoa comece a desligar-se paulatinamente da leitura desses livros. Fala que tal interesse é análogo àqueles que têm o álcool como guia, seu julgamento da realidade fica amputado, incorrendo em julgamentos falsos em relação às coisas do mundo. Nesse mesmo período relata a Mário de Sá-Carneiro, um de seus melhores amigos, em uma série de poemas e cartas, sua desilusão e desejos a corroer sua alma. Esta correspondência dura algum tempo, até o suicídio de Sá-Carneiro, com uma dose de estricnina.

Pessoa fica desolado com a morte de seu amado amigo. Com o luto sente-se incompetente para a vida e um mundo de sombras ameaça soterrá-lo. Frente às dores advindas da solidão, começa a acalentar o desejo de ter uma companheira. Este desejo aparece em diferentes períodos da vida de Pessoa, ele o nutre durante um tempo e o desinteresse incide.

Começa a namorar, nessa época, Ofélia Queiroz. O namoro é fugaz, dura um ano, e tudo indica que Fernando Pessoa saiu como entrou: virgo intacto. As questões relativas à sexualidade parecem não promover em Pessoa um estado anímico - estado relativo à vontade, ao ânimo, ao desejo. Quanto mais Pessoa se aproxima deste aspecto, um mundo de símbolos, mitos, crenças e temores parecem se aferrar em seu espírito. Tanto que, no final de sua vida nutre a crença, da "segunda vinda do Encoberto". O Encoberto seria Dom Sebastião ${ }^{1}$ que retornaria envolto em uma névoa a Portugal e com isso se daria o Quinto Império. ${ }^{2}$

Pessoa trazia em si, apesar de inúmeros conflitos, uma certeza quase absoluta que viria a ser um dos maiores poetas portugueses, queria ser da envergadura de Camões. Acreditava também que sua obra (difundida em revistas, almanaques, panfletos, e àquela época em poucos livros) ajudaria Portugal a

1. Dom Sebastião desaparecido em 1578 teria retornado em 1888. Sua segunda vinda estava sendo calculada por Fernando Pessoa que não precisou data, tampouco os espíritos com quem conversava souberam dizê-lo. Fato é que o sebastianismo existe ainda hoje em Portugal, muitos ainda o esperam.

2. O chamado Quinto Império seria a continuação do Grego, o de Roma, o da cristandade, e da Europa pós-renascentista. Este Quinto Império, segundo Pessoa, seria primordialmente espiritual e reinaria sobre toda a Europa.

Rev. Latinoam. Psicopat. Fund., São Paulo, v. 15, n.3, p. 618-622, setembro 2012 


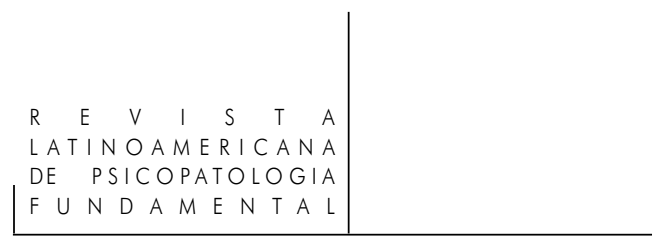

modernizar-se, inscrevendo no imaginário português um pensamento vanguardista e livre, sem estar atrelado ao pensamento da Velha República e ao salazarismo que começava a minar o espírito de uma parcela do povo português.

Falar em Pessoa é falar de um homem a viver como poucos, a trabalhar como muitos e a morrer sendo único. Sua personalidade, antes mesmo de ser objeto de investigação, deve ser admirada como a de um ser humano a levar ao zenith sua sensibilidade e trabalho com o propósito de gerar no coração do homem e em seu espírito o reconhecimento de tudo aquilo que não pode ser relegado. Sendo $o$ homem, um ser frágil, Pessoa aliou-se a tantos outros para tentar convencê-lo de seu amor, solidão, desespero e estranhamento diante de um universo sem fim e sem começo.

\section{Referências}

CAeiro, A. O guardador de rebanhos e outros poemas. São Paulo: Landy Editora, 2006.

Zenith, R.; Vieira, J. Fotobiografia de Fernando Pessoa. São Paulo: Companhia das Letras, 2011.

Fabiano Massarro Salvador

Mestre em Psicologia Clínica pela PUC-SP

Av. Regente Feijó, 1000 - Jd. Anália Franco

03342-000 São Paulo, SP, Brasil

e-mail: massarro@ig.com.br

Rev. Latinoam. Psicopat. Fund., São Paulo, v. 15, n.3, p. 618-622, setembro 2012 